\title{
Transportes Turísticos da Ilha de Paquetá: sensações, descobertas e motivações
}

Vinícius Alves Carmo

\begin{abstract}
Resumo
O trabalho aborda a conceituação da experiência turística, apresentando a vivência da serendipidade durante a prática turística e o projeto da economia da experiência lançado entre o Sebrae e o Ministério do Turismo. Além de apresentar a Ilha de Paquetá a partir de sua geografia em conjunto com sua história, mostra-se o panorama da questão das charretes a partir de 2010. E, por fim, o acervo turístico e paisagístico de Paquetá é identificado. Como conclusão, a pesquisa de campo demonstrou que a motivação, as lembranças e as sensações obtidas pelos turistas durante a visita à ilha são geradas pela possibilidade do conhecimento de curiosidades e atrativos naturais da Ilha, realização de passeio cultural com familiares, práticas de lazer e fotos, e não pelo uso dos transportes. Palavras-chave: Experiência; Ilha de Paquetá; Transportes.
\end{abstract}

\begin{abstract}
Touristic transportation in the Paquetá Island: feelings, discoveries and motivations

This study discusses the concepts of tourist experience, presenting the serendipity experience during tourist practice and the experience economy project launched by Sebrae and the Ministry of Tourism. Besides presenting Paquetá Island's geography along with its history, this study presents the outline of the horse-drawn cart issue from 2010 on. Lastly, Paquetás touristic and landscape collection is identified. As a conclusion, the field research demonstrated that motivation, memories and feelings experienced by tourists during the island visitation are created by the possibility of getting to know the Island's natural attractions and curiosities, of doing a cultural tour with relatives, of leisure practices and photos, and not by the use of transportation.
\end{abstract}

Keywords: Experience, Paquetá Island, Transportation.

\section{Resumen}

Transportes turísticos en la Isla de Paquetá: las sensaciones, los descubrimientos y las motivaciones

El trabajo aborda el concepto de la experiencia turística, con la experiencia de la casualidad durante el proyecto de la práctica de turismo y economía de la experiencia lanzado entre Sebrae y el Ministerio de Turismo. Además de presentar la isla de Paquetá, por la geografía, junto con su historia, muestra la visión general de la cuestión de los coches de caballos a

a. Graduando em Turismo e MBA em andamento em Gestão de Serviços com ênfase em Eventos pela Faculdade de Turismo e Hotelaria da Universidade Federal Fluminense. Atualmente faz estágio para a Pró-Reitoria da Universidade Candido Mendes, vinculado ao Instituto de Turismo e Entretenimento, e realiza serviços para a Associação Brasileira de Gestão Cultural no Centro Cultural da mesma universidade. Participa de grupos de pesquisa nas seguintes áreas: Cultura Popular e de Massa, Território e Gestão, Hospitalidade Contemporânea e Lazer e Entretenimento. Niterói, Rio de Janeiro, Brasil. E-mail: viniciusalves@id.uff.br 
partir de 2010. Y, por último, la identificación del turista y la recogida escénica de Paquetá. La investigación de campo ha demostrado que la motivación, recuerdos y sensaciones obtenidas por los turistas durante su visita a la isla, son generados por la posibilidad del conocimiento de curiosidades y atractivos naturales de la isla, la realización de recorrido cultural con la familia, actividades de ocio y fotos y no para el uso del transporte.

Palabras clave: Experiencia; Paquetá; Transporte.

\section{INTRODUÇÃO}

A placidez encontrada na Ilha de Paquetá acabou por inspirar compositores e escritores, cenários de novelas e a construção de casas de veraneio para governadores do estado do Rio de Janeiro. Tais fatos, somados às opções de lazer e entretenimento, fazem do bairro um espaço com grande potencial turístico. De acordo com Silva (2004), Paquetá apresenta bens imóveis preservados e íntegros, com edificações permanentes, arquitetura e traçado urbano preservados, o que a faz pertencer ao grupo de lugares com traços e características únicos.

Neste trabalho, tem-se como objetivos específicos indicar hábitos, costumes e traços culturais revividos pelos turistas ao utilizar o transporte de Paquetá; apontar as possíveis experiências, descobertas e sensações causadas pelos transportes turísticos; verificar as condições dos transportes como atrativos durante os passeios de charretes elétricas, eletrotáxi, trenzinho, pedalinho e bicicleta, e considerá-los como meios tangíveis que levam os visitantes a recordar momentos cinematográficos, literários, cenários de novelas e lugares.

A pesquisa bibliográfica foi importante para o trabalho, pois, em um primeiro momento, contribuiu para a descrição e exemplificação da experiência turística e, em um segundo momento, embasou a possibilidade de viver a experiência a partir do contexto histórico e conceitual em que a Ilha de Paquetá está inserida. Autores de renome na área de análise estrutural do turismo e da experiência turística, assim como o levantamento bibliográfico histórico e turístico da Ilha de Paquetá, são abordados, dando base para o maior entendimento dos transportes da ilha. As obras foram estudadas e pensadas para se relacionarem com o campo de pesquisa e fornecer a base para o desenvolvimento das ideias propostas. Para o entendimento da relação entre teoria e prática, fez-se pesquisa in loco com visitantes após sua chegada em Paquetá. Foram consideradas, ainda, avaliações de usuários do site TripAdvisor a partir de comentários e dicas.

Para dar conta da proposta descrita, o trabalho se divide em cinco partes. A primeira, esta que se lê, traz considerações iniciais. A segunda define a experiência turística. Dando prosseguimento, na terceira parte apresenta-se a Ilha de Paquetá, a formação de sua identidade e as características que podem defini-la como espaço para lazer, turismo e entretenimento. A quarta parte relata a pesquisa realizada in loco, assim como seus resultados. E, por fim, a última parte traz as considerações finais.

\section{EXPERIÊNCIA TURÍSTICA E A BUSCA DA NOVIDAdE}

A serendipidade é caracterizada pelas descobertas feitas ao acaso dentro da atividade turística, como a arte de viver algo que ainda não foi vivido (Saldanha, 
Fraga, \& Santos, 2015). A origem do termo remonta à lenda oriental “Os três príncipes de Serendip", que conta a trajetória de viajantes fazendo descobertas felizes, sem objetivos reais. É uma forma de estado mental momentâneo em que o indivíduo está aberto à experiência, à apuração da imaginação e à afirmação do senso de curiosidade. 0 sucesso de uma viagem é proporcional ao bem-estar pós-viagem do turista em resposta à monotonia de seu dia a dia corrido no mundo contemporâneo (Saldanha, Fraga, \& Santos, 2015).

Ao experimentar a serendipidade o indivíduo cria suas asas e regras e altera caminhos tradicionais, vivendo a fantasia, aguçando a consciência e a imaginação e tendo prazer ao estar fora do habitual (Saldanha, Fraga, \& Santos, 2015). Tratase de uma mistura entre a sagacidade e o acaso, compreendendo os sinais, interpretando-os e realizando descobertas ao expandir horizontes de conhecimentos, com uma mente mais aberta às diferenças, ao desconhecido ou esquecido no tempo, ao realizar novas aventuras e desfrutar de novidades. A descoberta ao acaso é a afirmação de que embora algo possa ser imaginado durante a viagem, experiências não planejadas marcarão e se tornarão inesquecíveis pela história da viagem proporcionada por operadores turísticos via planejamento do produto turístico. 0 mundo de viagem não está ligado diretamente, ou seja, quando o turista encontra algo diferente do habitual. É comum e o aumento no número de turistas sem planos e pacotes formais de viagem, ou seja, sem a necessidade de intermediadores para planejar sua viagem.

Para Saldanha, Fraga e Santos (2015, p. 302), "destinos e atrações turísticas podem ser ambientes férteis para a ocorrência da serendipidade e isto pode ser estimulado no contexto do mercado turístico". Ao olhar a história da viagem percebe-se que entre 1870 e 1940 ocorreram mudanças na cultura da viagem com a incorporação ao capitalismo popularizando-se pelas massas. No campo turístico, as experiências memoráveis acontecem pela relação com o meio ambiente e com a variada diversidade cultural. É possível perceber como o turista irá se comportar quando tiver contato com o diferente "ao se escolher o uso de meios de transportes e os trajetos para acesso e circulação em destinos turísticos" (Saldanha, Fraga, \& Santos, 2015, p. 302).

Há vários tipos de experiências turísticas, entre elas a experiência cognitiva, baseada nas experiências locais, na compreensão da novidade e na interação social, e a experiência afetiva, baseada em emoções positivas, como a felicidade e a excitação. Entretanto, nem toda experiência é memorável e bem-vinda para o turista se o destino não corresponder com as suas expectativas.

Destinos turísticos na periferia podem decepcionar um visitante quando ele encontra o local pouco acessível e estruturado para a atividade turística. Nesse ponto, destaca-se a importância de uma boa oferta de transporte turístico aliada à boa infraestrutura de apoio para melhorar a imagem local, seja em ilhas, arquipélagos, montanhas. Por fim, também é importante tornar desenvolvido o destino, estabelecendo critérios de competitividade regional.

Saldanha, Fraga e Santos (2015) afirmam que é possível compreender com êxito a maneira que experiências memoráveis e a serendipidade como atributo do transporte podem ser exploradas, percorrendo caminhos diversos dos tradicionais ou mesmo programados em roteiros de agências de viagens.

Um aspecto fundamental da atividade turística é oferecer à demanda uma mudança de hábito, uma experiência incomum, que não se faz presente na vida 
diária do turista. De acordo com Trigo (2010, p. 35), “a viagem precisa superar a banalidade, os aspectos triviais, estereotipados e convencionais e estruturar-se como uma experiência que nasça da riqueza pessoal do viajante em busca de momentos e lugares que enriqueçam sua história".

Krippendorf (2003) afirma que o indivíduo se torna turista em razão de sua curiosidade, buscando descobrir e aprender para sair de sua rotina. Esta vontade de viajar pode advir da falta de equipamentos ou infraestrutura de lazer próxima a sua residência, que o leva ao consolo externo. Assim, em paralelo com férias e folgas, viajar a lazer pode impulsionar o descanso e a experiência de estranhamento do cotidiano.

O termo usado para personalizar os produtos turísticos, tendo como protagonista o turista que deseja ir além do que é normalmente comercializado em agências de viagem e propagandas do destino, não se acomodando com o que é tradicional e desejando ir até as raízes dos lugares que visita, denomina-se "turismo de experiência".

A compreensão da experiência como um diferencial a ser oferecido aos consumidores foi um avanço importante em termos mercadológicos, mas, como em tantos outros estudos e tentativas de denominação ou classificação na área de gestão e negócios, o termo caiu em um modismo superficial, que, em boa parte, neutralizou os avanços conquistados. (Trigo, 2010, p. 29)

A experiência turística é iniciada por um choque de prazer que gera semelhanças com tempos anteriores da vida do turista, a ponto de despertar emoções com a experiência do presente (Turner, 1989).

A experiência é uma maneira de representação do que acontece no cotidiano na qual o indivíduo tem o prazer de estar em lugares diferentes do que é comum na sua vida rotineira ou no dia a dia. 0 turismo é gerado como fenômeno composto por agentes sociais e movimentos de ida e volta, voluntários e a lazer, em busca de novas sensações, com o fim de experimentar outras perspectivas culturais (Panosso Netto \& Gaeta, 2010). A experiência individual de uma pessoa no espaço, urbano ou natural, é resultado de uma experiência turística. Tem-se constatado que o campo do turismo é uma área ampla para a investigação de abordagens experienciais. Existem muitas emoções em uma atividade turística: "dominada por uma busca da felicidade, talvez poucas atividades fossem tão reveladoras - em todo o seu ardor e seus paradoxos - como nossas viagens" (Botton, 2003, p. 17).

Ainda de acordo com Turner (1989), há a necessidade de uma maior compreensão quanto ao significado do termo "experiência" para que se possa entender seu papel no fenômeno turístico. 0 autor sinaliza também a existência de uma dualidade entre "uma experiência passiva e aceitação dos fatos" (p. 174).

Ao viajar, o deslocamento local gera novas perspectivas no indivíduo. Graburn (1989, p. 54) afirma que "frequentemente voltamos aos nossos papéis anteriores com uma sensação de shock cultural". Após uma experiência, voltamos diferentes, se levarmos em consideração que passamos por rituais, visando um momento livre de cuidados, preocupações e também rico de novas perspectivas e esperança. Esse rito transforma o estranho em amigável e faz esquecer o que é a rotina (Dawsey, 2005). 
Há três ritos de passagem retratados. De acordo com Turner (1989), o turista atravessa momentos durante a viagem e o momento do desfrute do destino. Ele tem a oportunidade de sair do seu cotidiano durante o lazer, a viagem e a excursão e voltar para o cotidiano habitual, como ilustrado na Figura 1.

Figura 1 - Rito de passagem

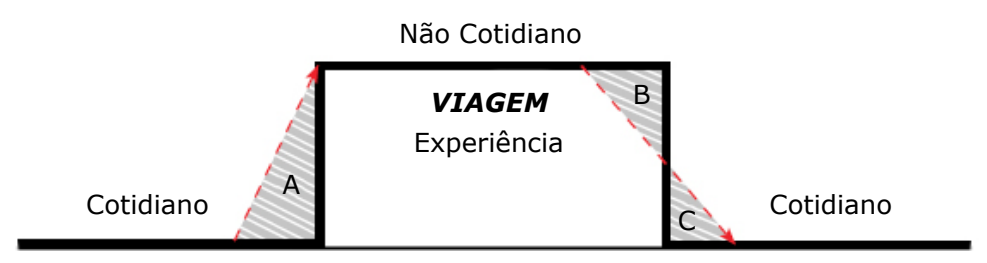

Fonte - Santos, 2011 (citado por Pezzi e Vianna, 2013)

A área A representa a margem indicativa do momento de transição do turista do cotidiano para o não cotidiano. É onde ele começa a entrar na fase de experimentação da viagem. A área B é o ponto de transição do não cotidiano para o cotidiano, no qual o turista chega ao ápice de experimentação da viagem e começa o ritual de retorno. A partir de $\mathrm{B}$, chega-se à área $\mathrm{C}$, onde o turista volta totalmente para a sua realidade de vida.

O primeiro e o segundo estágio, real e realidade, são considerados semimomentâneos. A vida como experiência, dentro da sequência conceitual, relaciona a contemplação da realidade ao real já concretizado, já considerando o indivíduo inserido no fluxo temporal da vida ao experimentar o novo. Dessa forma, a projeção da realidade seria o que foi apreendido daquilo que foi vivenciado no momento da experiência e relações nesse processo, ou seja, os significados sobre a realidade constituída.

Do ponto de vista de questões antropológicas, as diferenças temporais acontecem em razão da dinamicidade processual, instituída numa perspectiva cronológica na qual o presente é levado ao "momento passado". Assim, a cultura estaria fincada numa linearidade, mas em transformação, modificando-se (Laraia, 2001).

A terceira fase, ou estágio conceitual, é a expressão considerada como molde de sentidos feito por meio de reflexões da experiência estruturada. 0 ponto de vista estaria relacionado a fatos antigos que, articulados em pedaços, são construídos por sentidos subjetivos da experiência à realidade. Levando em consideração que o caráter constitutivo da relação expressão e experiência é dialético, pois experiências constroem expressões na proporção de bases vividas pelo individuo correlacionadas ao seu "mapa", influenciador do modo interpretativo da relação mundo e modo de expressão. Em conseguinte, as experiências conduzem expressões determinantes, além de mapas simbólicos dos sujeitos. A experiência é culturalmente construída, enquanto o entendimento pressupõe experiência (Bruner, 1991).

A experiência é posta também em relação com o consumo do produto turístico. Segundo Ruschmann (2000), as experiências ocasionadas pelo fenômeno turístico seriam o resultado dos produtos turísticos. Algumas pessoas têm a tradição de guardar como recordação lembranças que representaram momentos vividos. Nesse sentido, é possível destacar a correlação entre experiência e emoção, pois 
no momento em que o passado se torna inesquecível, surge a necessidade de salvar esse momento. Acredita-se que a experiência é tão inesquecível a ponto de o turista ser visto como elo principal.

Gordon (1986) afirma que a experiência ocorre como resultado do encontro, de se submeter ou viver situações. "Elas devem estimular os sentidos, o coração e a mente" (Schmitt, 1999, p. 26-27). A experiência visa entender aquele que visita o espaço e passa por experiências por um tempo. 0 espaço interfere na percepção e experiência do indivíduo, levando a materializar o momento que foi visto possivelmente por meio de consumo de produtos.

\section{Economia da experiência: as emoções e os quatro sentidos}

O ramo turístico no Brasil logo passou a agregar o conceito de experiência como filosofia político-econômica desenvolvida por meio do projeto e estudo na academia da economia da experiência: "fazer com que o turista se sinta especial, e não apenas 'mais um', dentro de um grande grupo que se desloca guiado por rigorosas relações de comando que diluem a possibilidade de qualquer envolvimento afetivo com o destino" (Brasil, 2010, p. 7).

Na expectativa de satisfação emocional, as pessoas buscam produtos e serviços que ilustram uma história e deixam a viagem ainda mais inesquecível e emocionante. Pine e Gilmore (1999) tentam entender o perfil do consumidor dos séculos XX e XXI. Segundo os autores, tivemos a era agrícola, industrial e de serviços, e agora vivemos um quarto ciclo, numa perspectiva de compreensão sensorial e imaginativa. 0 consumidor passa a exibir uma personalidade de acordo com o mercado. Pelo menos quatro variáveis podem ser exploradas nos estudos da experiência turística: entretenimento, aprendizagem, contemplação e evasão.

Figura 2 - Domínios da experiência

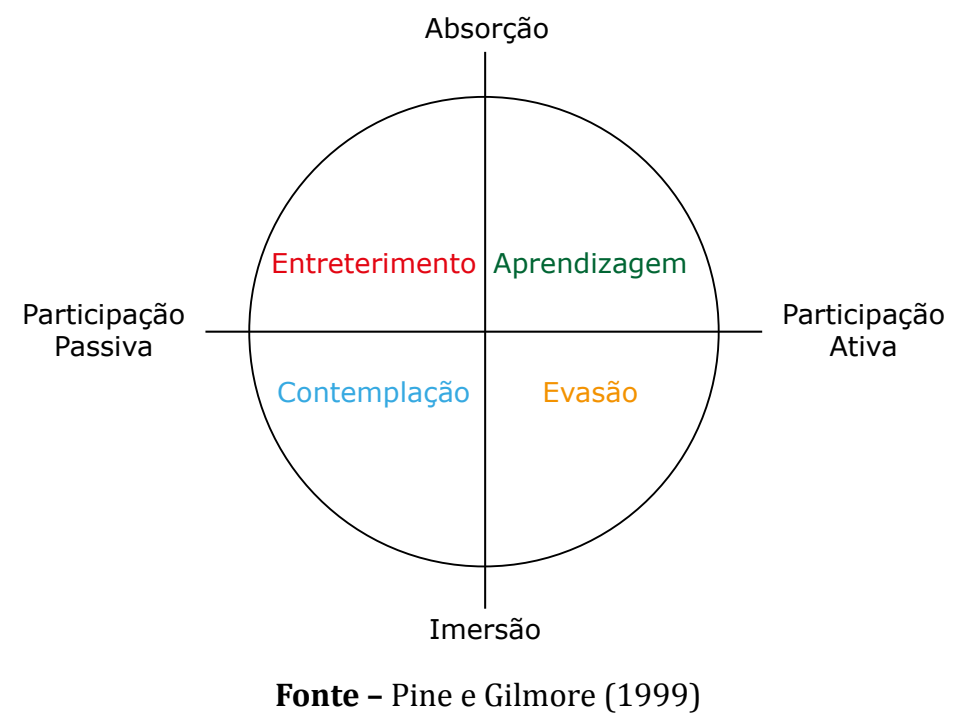

Podem-se observar os eixos verticais e horizontais, tendo a participação ativa ou passiva do indivíduo perante a experiência. 0 choque é um ponto determinante 
para compreender o sentido do cenário paisagístico entre distúrbio e harmonia. No término dessa vivência pode acontecer um recomeço, uma nova significação manifestada por meio de uma restauração da normalidade ou cisão com o passado (Turner, 1989).

A economia da experiência é a forma que o consumidor paga para desfrutar de grandes momentos, tendo como objetivo a satisfação de seus desejos e o encontro com ideias. 0 turista, ao visitar a praia, tem o interesse de ficar com aparência de bem-estar e qualidade de vida, assim como o que visita uma vinícola quer desfrutar a vista do local e satisfazer seu paladar no momento de consumo do produto. Quando o visitante participa de maneira ativa na região turística, ele pode ficar à mercê de suas emoções e sensações, favorecendo seu bem-estar, gerando valor ao produto e incentivando a atividade local.

Os turistas deixaram de ser espectadores para se tornar atores, e os produtos que oferecem a possibilidade desse turista ser ativo fazem a diferença. Atualmente, a economia induz o mercado a tomar novos rumos quanto à forma como um produto será colocado, oferecido e vendido em tempos de consumidores atentos aos seus direitos e desejos. No século XXI, as sociedades estão cada vez mais com seus passos marcados e imortalizados com o advento dos recursos digitais, como a fotografia, ou recursos físicos, como souvenirs, potencializando os lucros dos destinos (Pine \& Gilmore, 1999).

É fundamental e decisiva a atenção de funcionários de um empreendimento turístico no momento da venda e da execução do serviço, que pode ser medido pela quantidade de gorjetas ou por avaliações em sites de opiniões, a exemplo do TripAdvisor, que hoje serve de guia-padrão para os turistas planejarem os seus passos. 0 turista está preparado para compensar um bom serviço, basta receber um bom produto e obter satisfação.

Segundo Isherwood (2004), poder e querer o consumo de produtos é fruto da nossa sociedade atual e pós-industrial, diferentemente da sociedade pré-industrial. 0 consumo tem o valor simbólico de representação de desejos sociais e pertencimento à sociedade urbana. 0 consumidor goza do desejo de adquirir o produto para fazer parte da relação de amigos de trabalho, classe e comunidade. Além disso, o indivíduo necessita de produtos intangíveis e dos mais variados aspectos para sanar seus desejos (Urry, 1999).

De acordo com Viveret (2006), o turista está voltado muito mais para o ter do que o ser, ou seja, não está atento às suas reais necessidades, mas sim a seus desejos de posse e de exibição criados pelo meio social e competitivo que se enquadra a sociedade contemporânea.

Há três reações dos clientes que são: (i) cognitiva, referente à crença do produto percebido; (ii) emocional, em relação à atitude do ambiente de prestação do serviço; (iii) física, de acordo com conforto/desconforto do ambiente (Brasil, 2007).

Por se basear em diferentes personalidades, expectativas em relação ao lugar e estado de espírito, a medição desses fatores também necessita de moderação. Dentro dessa questão, para Brasil (2007, p. 4),

a personalidade pode influenciar as reações do cliente/funcionário em relação à ambientes lotados, da mesma forma que um cliente em um final de semana pode reagir à lotação de um restaurante de maneira diferente à reação de um dia de trabalho, no qual esteja pressionado pela falta de tempo. 


\section{PAQUETÁ, HISTÓRIA E IDENTIDADE}

Paquetá, a principal ilha do arquipélago de mesmo nome, está situada ao nordeste da Baía de Guanabara, a uma distância média de 15 km da Praça XV, localizada no centro da cidade do Rio de Janeiro. Seu nome foi criado pelos índios tamoios, onde "pac" (paca) e "eta" (muitas), "lugar de muitas pacas", "muitas conchas" ou "muitas pedras". Entretanto, escritos afirmam que a ilha possui muitas pacaranas, animais da família das pacas.

Paquetá abrange uma área de pouco mais de $1,2 \mathrm{~km}^{2}$, repartida em duas partes, interligada por um estreito denominado Ladeira Vicente, com cerca de $100 \mathrm{~m}$ de largura, e que dá à ilha a forma de um oito visto de cima, direcionando a posterior divisão em sesmarias do território e marcando a diversidade do cotidiano social entre os dois campos. No seu perímetro geográfico é possível desfrutar de opções de lazer em conjunto com a sensação de volta ao passado proporcionada pela tranquilidade de suas singelas ruas de terra.

A ilha foi historicamente divulgada como lugar de descanso e lazer, como cenário exótico e de exaltação da paisagem. 0 cuidado com a preservação pode ser visto nos parques onde circulam somente veículos como bicicletas, eletrotáxis, trenzinhos e charretes elétricas. A Ilha de Paquetá, embora pequena em espaço geográfico, apresenta uma diversidade cultural única e variada.

A Ilha de Paquetá, "a mais bela da Baía de Guanabara" (Les Guides Bleus, 1955), foi antiga morada de índios e nobres que construíram a história do país. 0 primeiro registro que se tem da ilha é de 1555, quando o frade franciscano André Thevet, cosmógrafo da expedição de Nicolas Durand de Villegagnon, descobriu Paquetá em sua missão para fundar a França Antártica. 0 local foi reconhecido pelo rei da França e registrado no cartório de Paris em 1556, em um registro anterior à própria fundação da cidade do Rio de Janeiro.

No ano de 1565, foi fundada a cidade de São Sebastião do Rio de Janeiro, entre os morros Cara de Cão e Pão de Açúcar, como consequência da vinda de Estácio de Sá ao Brasil para cumprir uma missão colonizadora que tinha como principal objetivo enfrentar e derrotar os franceses e se apossar de novas terras. A partir da aliança com indígenas da etnia temiminós, Estácio de Sá venceu os adversários que haviam se aliado a outra etnia indígena.

Estácio de Sá doou a Ilha de Paquetá sob a forma de duas sesmarias a dois de seus companheiros de viagem: Inácio de Bulhões e Fernão Valdez. 0 primeiro ficou com a parte norte, que teve como marco a formação da Fazenda São Roque, com extensa área agrícola e criação de gado, hoje denominada bairro do Campo pelos comunitários. 0 segundo ficou com a parte sul, que teve colonização mais rápida. Paquetá é curiosa por não existir carros particulares, e muitos frequentadores adequam-se ao uso dos transportes para locomoção, transportes de compras e mercadorias agregados pelo turismo como atração de aventureiros com expectativas de novas descobertas e novos ares.

Graças à tranquilidade, Paquetá é uma opção para as pessoas saírem do intenso movimento cotidiano da metrópole urbana carioca, cheia de problemas diários. 0 clima ameno, sendo alvo potencial de recomendações médicas por sua tranquilidade, proporcionou estadias durante um tempo, preservando a saúde psicológica de seus visitantes. 
Segundo o último senso demográfico (IBGE, 2010) a Ilha de Paquetá concorre com Petrópolis e Teresópolis ao atrair moradores como ponto de residência e oferecer para o cidadão a possibilidade de fugir de congestionamentos, preços inflacionados de imóveis e violência urbana. É comum presenciar crianças na rua brincando, pessoas nas portas de casa tarde da noite, sem perigo e registros de algum tipo de violência.

A omissão do poder público ao longo dos últimos anos na manutenção dos patrimônios de Paquetá foi determinante para deteriorar espaços de memória coletiva, levando frustração e tristeza para os residentes que possuem alguma identidade com o local e perda de espaço em guias e roteiros turísticos oficiais do Rio de Janeiro. As últimas reformas de embelezamento na ilha aconteceram no governo de Carlos Lacerda, então primeiro governador do estado da Guanabara.

Nos últimos anos, as charretes, tradicionais na Ilha de Paquetá, sofreram pressões de ambientalistas quanto às condições de trabalho dos cavalos. Além disso, a decadência da atividade e do negócio foi potencializada pelos altos custos com a manutenção da atividade, como medicamentos, alimentação, remédios e garantia das condições mínimas para abrigar os cavalos. A cocheira que abrigava os cavalos, construída pela Secretaria Municipal de Meio Ambiente (Smac) em 2003, na Praia dos Frades, sem possuir manutenção adequada, permitia que esgoto, urina e fezes dos animais chegassem à praia.

Figura 3 - Charretes a cavalo

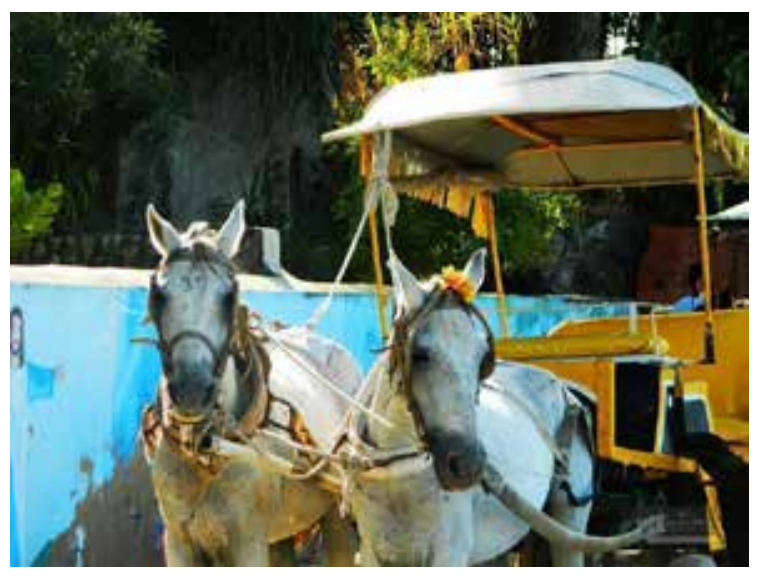

Fonte - Bastos (2012)

O uso das charretes, puxadas e movidas pelos cavalos, provocou grande debate na ilha, a partir da discussão de vereadores da cidade do Rio de Janeiro, que elaboraram o projeto de Lei Municipal no 144/2013 para proibir a utilização desses animais em Paquetá.

Foram cerca de quatro debates na câmara parlamentar com simpatizantes da causa animal, como artistas, ambientalistas e celebridades, e pessoas contrárias à efetivação do projeto de lei. 0 debate envolveu a Secretaria Especial de Promoção e Defesa dos Animais (Sepda), a Ordem dos Advogados do Brasil (OAB), o Ministério Público, o Conselho Regional de Medicina Veterinária (CRMV) e até uma comissão de Brasília, contrários a utilização de animais (Araujo, 2016).

A cocheira estava interditada pela Defesa Civil desde 2010, após deslizamento de parte de seu muro, levando a óbito um animal. A decisão de fim da operação 
foi tomada depois de prolongadas negociações entre a OAB-RJ e a Associação dos Proprietários e Condutores de Charretes da Ilha de Paquetá (Charretur). Após queixas, pressões e a ineficiência na manutenção e no cuidado à saúde dos animais, alguns ambientalistas e manifestantes levantaram a bandeira contra o uso de animais nas charretes, utilizadas como meio de transporte desde o século XIX. As charretes foram retiradas de circulação pela Prefeitura do Rio por medida de lei sancionada pelo prefeito do Rio, Eduardo Paes, em 19 de maio de 2016. Com o fim do transporte de tração animal, foi estabelecido o uso de charretes elétricas (David, 2016).

Foi importante o projeto do vereador Eliomar Coelho, que ao sugerir a substituição dos cavalos por charrete elétrica, favoreceu o projeto de lei para a extinção do uso dos animais. "Adotados em vários países como substitutos de veículos que utilizam a tração animal, encontra forte resistência de alguns moradores da ilha, que temem acidentes e o crescimento desordenado da atividade" (Araujo, 2016, p. 32).

Figura 4 - Charrete elétrica

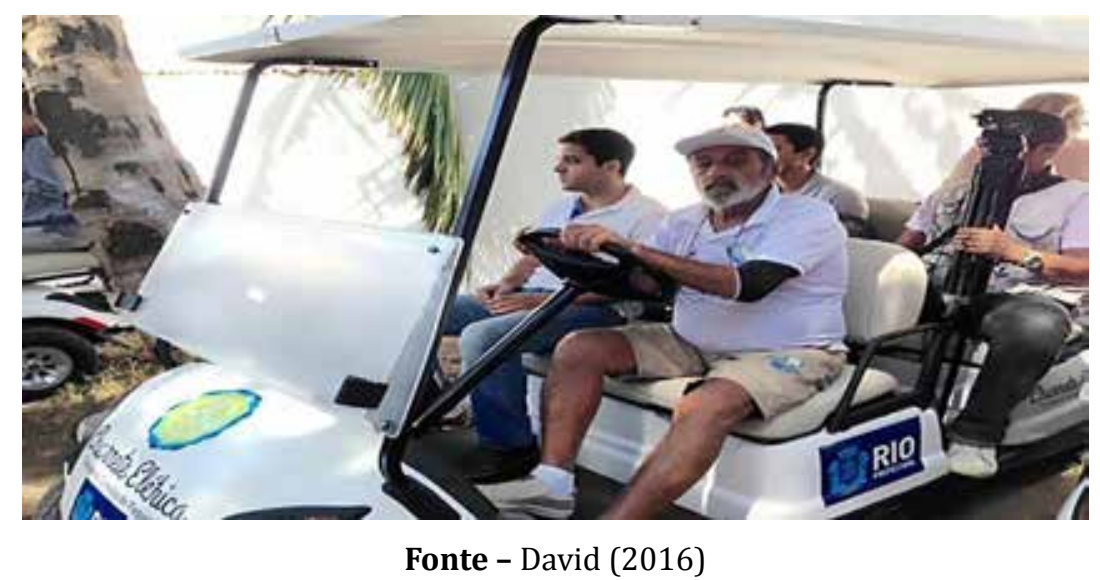

\section{PERFIL DO VISITANTE, TRIPADVISOR E PROJETO DA EXPERIÊNCIA}

Foi realizada pesquisa in loco com 51 visitantes que acabavam de visitar e utilizar os meios de transporte da ilha, experimentando os serviços ofertados. Todos estavam deixando Paquetá em direção ao terminal de barcas da Praça XV. As entrevistas aconteceram no dia 22 de setembro de 2016, entre $11 \mathrm{~h} 30$ e $18 \mathrm{~h} 40$.

Os visitantes receberam muito positivamente a entrevista. 0 campo de pesquisa também facilitou o trabalho, pois foram aproveitados os momentos em que os visitantes estavam retornando de Paquetá nas barcas com destino à Praça XV, trajeto que tem duração exata de setenta minutos. Muitos visitantes abordados, por não estarem ocupados e entretidos com alguma atração no momento da abordagem, não demonstraram receio e foram bem receptivos durante todo o processo. Pôde-se obter, dessa forma, atenção, tranquilidade e compreensão para responder todas as perguntas elaboradas.

Durante a entrevista, muitos demonstraram ter poucos conhecimentos sobre Paquetá, pois, se tivessem uma boa experiência, poderiam gerar mais satisfação e contribuir de maneira eficaz nas respostas da pesquisa. A história é capaz de gerar vida, é o que diz Horn e Germinari (2010, p. 118), que afirmam que o 
conhecimento local "desenvolve análise de pequenos e médios municípios, ou de áreas geográficas não limitadas e não muito extensas".

A identidade local, quando conhecida pelo visitante, é capaz de iniciar o processo de construção de memória. 0 saber da história local inicia o marco para compreensão das diferenças, mesmo submetido a mudanças. A experiência do indivíduo é ampliada quando relacionada a estruturas temporais, ultrapassando o tempo de vida, demonstrando sua importância dentro da cultura local no passado, presente e futuro (Germinari \& Buczenko, 2012).

O questionário aplicado na pesquisa continha dez perguntas (Quadro 1) que levavam em média dez minutos (um minuto por resposta) para serem respondidas. 0 perfil dos entrevistados foi bem variado, com pessoas de todas as idades. Após a abordagem para a entrevista, o modelo, a temática e os fins do trabalho eram apresentados. 0 esclarecimento deixou os visitantes tranquilos para contribuírem de forma consciente.

Quadro 1 - Perguntas da pesquisa

\section{Local de residência \\ ( ) Baixada Fluminense ( ) São Gonçalo \\ ( ) Niterói ( ) Outros \\ ( ) Rio de Janeiro (cidade)}

2. Sexo

( ) Masculino ( ) Feminino

\section{Idade}

( ) de 18 a 24 anos ( ) de 45 a 64 anos

( ) de 25 a 44 anos ( ) 65 anos ou mais

\section{Estado civil}

( ) Solteiro ( ) Divorciado/Separado

( ) Casado ( ) União estável

( ) Viúvo

\section{Nível de escolaridade completo}
( ) Sem escolaridade
( ) Especialização
( ) Ensino Fundamental
( ) Mestrado
( ) Ensino Médio
( ) Doutorado
( ) Ensino Superior
( ) Pós-doutorado

\section{Renda familiar mensal}
( ) Até R\$ 880,00
（ ） Entre $\mathrm{R} \$ 5.281,00$ e $\mathrm{R} \$ 8.8000,00$
( ) Entre R $\$ 881,00$ e $\mathrm{R} \$ 2.640,00$
( ) Entre $\mathrm{R} \$ 8.800,00$ e $\mathrm{R} \$ 10.560,00$
（ ) Entre R\$ 2.641,00 e R\$5.280,00

\section{Motivações para ir à ilha}
( ) Andar na charrete elétrica
( ) Observar a paisagem
( ) Conhecer a ilha
( ) Pedalar
( ) Estudo
( ) Realizar piquenique em família
( ) Atravessar a baía de barca
( ) Passear de trenzinho
( ) Fazer roteiro cultural
( ) Utilizar o serviço de ecotáxi
( ) Ir à praia
( ) Outras 


8. Qual tipo de transporte você utilizou?
$\begin{array}{ll}\text { ( ) Barcas } & \text { ( ) Eletrotáxi } \\ \text { ( ) Bicicleta } & \text { ( ) Pedalinho } \\ \text { ( ) Charrete elétrica } & \text { ( ) Trenzinho }\end{array}$

9. Em relação à experiência com transportes na ilha de Paquetá você concorda (C) ou discorda (D)

( ) Lembra algum lugar famoso (país, ilha, cidade, bairro)

( ) Remete e lembra o passado da minha vida

( ) Lembra passagens da vida pacata e campestre

( ) Lembra algum desenho, livro infantil ou literário, filme, novela ou fato histórico

( ) Realizei novas aventuras

( ) Descobri novidades

10. Você voltaria à ilha de Paquetá?

( ) Sim ( ) Não

Fonte - Elaborado pelo autor

Por questões de proximidade geográfica, foram colocados no formulário a região da Baixada Fluminense, a cidade do Rio de Janeiro, os municípios de Niterói e São Gonçalo, e a opção "outros" para todos os demais municípios do estado do Rio de Janeiro e do Brasil. No dia da pesquisa, alguns grupos de excursões de cidades de outros estados do Brasil, como São Luís (MA), Juiz de Fora (MG), Petrópolis (RJ), Piúma (ES) e até da Região dos Lagos, como o município de Búzios, contribuíram com a pesquisa (Figura 5).

Figura 5 - Local de residência

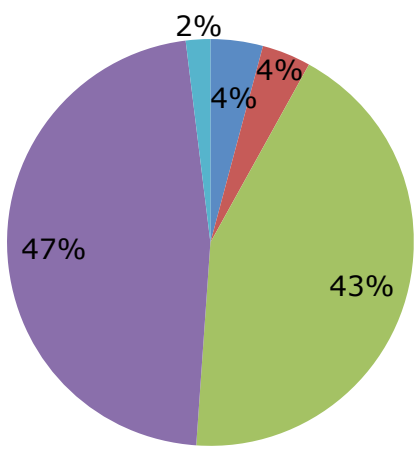

\begin{tabular}{|l|l|c|}
\hline & Região & Quantidade \\
\hline Baixada Fluminense & Baixada Fluminense & 2 \\
\hline $\begin{array}{l}\text { Niterói } \\
\text { Outros }\end{array}$ & Niterói & 2 \\
\hline $\begin{array}{l}\text { Rio de Janeiro (cidade) } \\
\text { São Gonçalo }\end{array}$ & Outros & 22 \\
\hline & Rio de Janeiro (cidade) & 24 \\
\hline & São Gonçalo & 1 \\
\hline
\end{tabular}

Paquetá recebe poucos visitantes das cidades da Baixada Fluminense e São Gonçalo. Quanto ao município do Rio de Janeiro, muitos visitantes eram de bairros do subúrbio carioca, como Realengo, Bangu e Campo Grande. Tais visitantes têm parentes morando em Paquetá ou tiveram residência no passado, permanecendo raízes de pertencimento à ilha, segundo os relatos dos entrevistados.

Dos visitantes abordados na pesquisa, 24 eram da cidade do Rio de Janeiro. A Baixada Fluminense e Niterói tiveram apenas dois representantes cada, enquanto o município de São Gonçalo obteve um respondente. 
A respeito da renda familiar mensal dos entrevistados, 21 pessoas (41\%) disseram receber entre 1 a 3 salários mínimos; em segundo lugar, 15 pessoas (29\%) disseram receber de 3 a 6 salários mínimos; na terceira colocação, 9 entrevistados (18\%) afirmaram estar na faixa de um salário mínimo; em penúltimo lugar, 5 entrevistados estariam na faixa de 6 a 9 salários; por último, apenas uma pessoa afirmou receber de 9 a mais salários mínimos (Figura 6).

Figura 6 - Renda familiar mensal



Até $R \$ 880,00$

Entre $R \$ 881,00$ e $R \$ 2.640,00$

Entre $R \$ 2.641,00$ e R\$ 5.280,00

Entre $R \$ 5.281,00$ e $R \$ 8.800,00$

Entre $R \$ 8.801,00$ e $R \$ 10.560,00$

\begin{tabular}{|c|c|}
\hline Porcentagem & Quantidade \\
\hline $18 \%$ & 9 \\
\hline $29 \%$ & 15 \\
\hline $10 \%$ & 5 \\
\hline $2 \%$ & 1 \\
\hline $41 \%$ & 21 \\
\hline
\end{tabular}

Fonte - Elaborado pelo autor

Os dados mostram que a Ilha de Paquetá tem predominância de visitantes das classes C e D (aparentemente com razoável poder de compra). Ao visitarem Paquetá, os turistas utilizaram serviços acessíveis financeiramente, como restaurantes e transportes de chegada e saída da ilha - como a barca, operada pela concessionária CCR Barcas. Alguns lugares são únicos por seu ambiente natural, paisagístico, atrativos culturais, história, por oferecer turismo de experiência, gerar sensação de tranquilidade e oportunidade de sair da rotina diária. Há, ainda, locais que já foram roteiro de viagem de amigos e até lugares que foram cenários da teledramaturgia.

Paquetá não foge a esse cenário muito procurado por turistas em busca de atrativos únicos, divulgados na mídia e em imagens e cartões-postais que incentivam o visitante a registrar o momento vivido por meio de fotos posteriormente divulgadas em redes sociais, mostradas para a família e guardadas como recordação. As motivações dos entrevistados para visitar a Ilha de Paquetá são listadas na Figura 7.

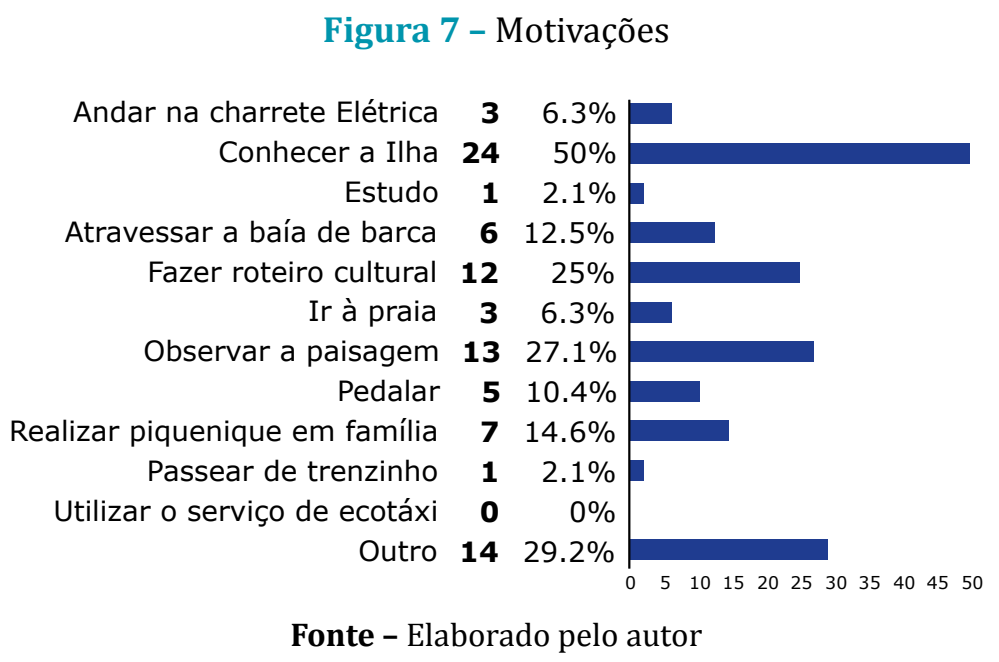

Como pode-se perceber pelos dados da pesquisa, apesar de importantes para a escolha dos turistas, os transportes não são os elementos mais atrativos para a 
visita a Paquetá. É importante esclarecer que todos os visitantes fizeram uso das barcas, que, no momento, são o transporte mais viável do ponto de vista da acessibilidade à ilha. A busca pela ilha acontece mais pela valorização de sua paisagem e arquitetura. Ademais, os entrevistados afirmaram ter realizado o passeio de bicicleta para se movimentarem, o que é incentivado pelo preço mais acessível. Os dados relativos aos transportes utilizados pelos entrevistados podem ser vistos na Figura 8.

Figura 8 - Tipo de transporte

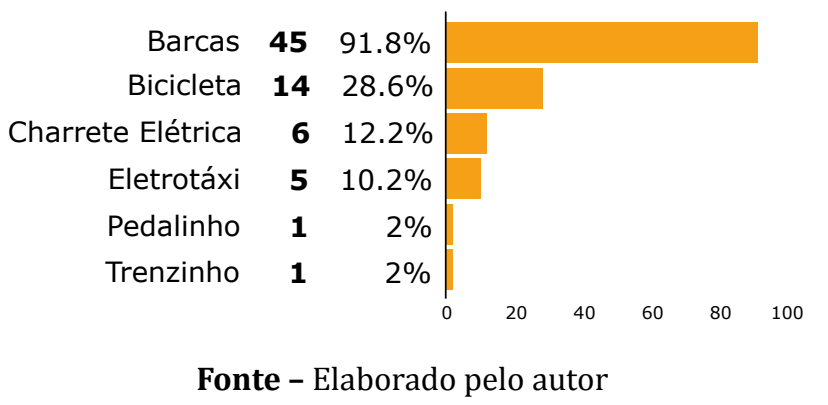

Na Figura 9 pode-se identificar que os entrevistados tiveram uma experiência não prevista durante o planejamento da visita e descobriram traços e curiosidades inóspitas, diferente de seu conhecimento cultural. Esse fato é um importante dado estatístico que confirma que Paquetá tem algo sempre peculiar que foge do conhecimento das pessoas. Caso não tenha vínculo familiar, residencial ou comercial com a ilha e não tenha pesquisado o histórico do destino antes da chegada, o visitante poderá se surpreender ao se deparar com informações históricas e curiosidades.

Figura 9 - Experiência dos entrevistados

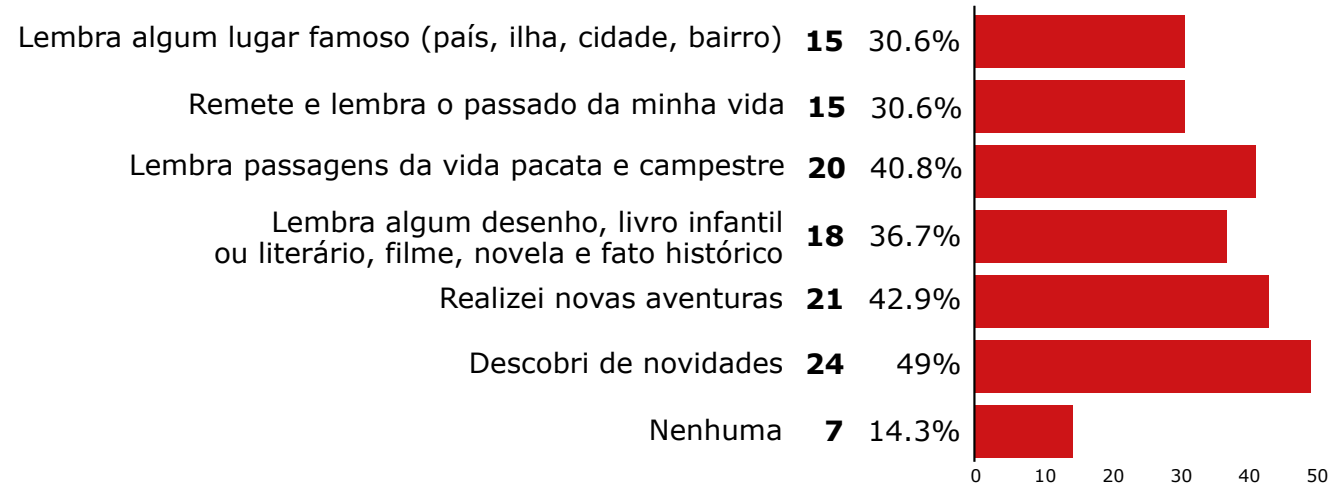

Fonte - Elaborado pelo autor

Embora Paquetá esteja necessitando de reparos em sua infraestrutura em razão de seu abandono, que a deixa em condições negativas nas avaliações dos consumidores/visitantes, é considerável que uma visão interdependente de seus atrativos ambientais, suas cores, aromas e arquitetura pode gerar satisfação e superação das expectativas. A partir da avaliação das pessoas, o conjunto macroambiental do lugar pode determinar a resposta do cliente ou até influenciar no desejo de retornar ao local. Os problemas operacionais de Paquetá, como coleta 
seletiva, iluminação pública, segurança e sinalização, podem influenciar negativamente no desejo de voltar.

Nessa perspectiva, Paquetá supera seus problemas recorrentes, menosprezados pelo poder público municipal, ao deixar seus visitantes com o desejo de retornar. Um fato curioso e importante para a ilha é a aparente superação das expectativas e contentamento com o lugar, mesmo com carências em serviços, como falta de opções de agências bancárias, ponto-chave para desenvolver e dinamizar um destino turístico. Todas as pessoas demonstraram interesse em retornar e desfrutar novamente das belezas de Paquetá. Os dados apresentados na Figura 10 mostram que o público visitante tem como objetivo a busca do lazer e contemplação da ilha em família ou com acompanhantes. Pode-se notar que tanto casados como solteiros estiveram em Paquetá com parentes e amigos. Nenhuma pessoa estava em passeio escolar ou em companhia de colegas de trabalho, ou em negócios.

Figura 10 - Estado civil/Acompanhantes

\begin{tabular}{|l|c|}
\hline \multicolumn{1}{|c|}{ Rótulos de linha } & Quantidade \\
\hline Casado & 17 \\
\hline Filhos & 2 \\
\hline Namorado(a) / noivo(a) / cônjuge & 3 \\
\hline Parentes e/ou amigos & 12 \\
\hline Divorciado/Separado & 5 \\
\hline Namorado(a) / noivo(a) / cônjuge & 1 \\
\hline Parentes e/ou amigos & 4 \\
\hline Solteiro & 21 \\
\hline Meus pais & 2 \\
\hline Namorado(a) / noivo(a) / cônjuge & 4 \\
\hline Ninguém, estou sozinho(a) & 1 \\
\hline Parentes e/ou amigos & 14 \\
\hline União estável & 1 \\
\hline Filhos & 1 \\
\hline Viúvo & 7 \\
\hline Parentes e/ou amigos & 7 \\
\hline
\end{tabular}

\section{Uma análise de Paquetá: Tripadvisor}

O TripAdvisor possui um mecanismo onde as pessoas que visitaram os destinos turísticos podem colocar suas opiniões. Trata-se de um site de viagens que fornece informações e opiniões sobre conteúdos relacionados ao turismo, com informações sobre hotéis, restaurantes e atrativos para quem deseja saber mais a respeito do local da próxima viagem (futuro turista). 0 Tripadvisor, que inclui fóruns com fotos, depoimentos, dicas e avaliações, foi um dos primeiros a adotar um conteúdo gerado pelo próprio usuário, que fornece a maior parte do conteúdo de todo o site. 0 site é um dos serviços mais populares na área do turismo e a maior comunidade de viagens do mundo, com mais de 84 milhões de membros 
e mais de 250 milhões de comentários. É também especializado em reservas e serviços (Estarque, 2015).

Figura 11 - Raio-X Tripadvisor

\begin{tabular}{|l|l|}
\hline Setor & Turismo \\
\hline Sede & Boston, EUA \\
\hline Receita & US\$ 1,2 bilhão \\
\hline Número de funcionários & 3.000 \\
\hline Usuários cadastrados & 84 milhões \\
\hline Visitantes únicos por mês & 350 milhões (5,3 milhões no Brasil) \\
\hline Comentários e avaliações & 250 milhões \\
\hline \multicolumn{2}{|c}{ Fonte - Estarque (2015) }
\end{tabular}

No site TripAdvisor há 647 avaliações de pessoas que estiveram na Ilha de Paquetá e postaram comentários sobre os serviços, infraestrutura, condições físicas da ilha, além de dicas de passeios, restaurantes e meios de hospedagens. É importante ressaltar a veracidade das informações, visto que o TripAdvisor preza pela veracidade do conteúdo. Até o dia 10 de novembro de 2016, do total de avaliações, 238 usuários avaliaram a ilha como excelente, 238 como muito bom, 104 pessoas como razoável, 24 como ruim e 19 como horrível. É importante dizer que estes respondentes não tiveram ligação com os respondentes da pesquisa anterior (realizada in loco em Paquetá).

Ao analisar o site e os comentários postados no ano de 2016, as pessoas que consideraram a ilha "excelente" citaram a beleza do local, tranquilidade, história, praia, descanso e relaxamento. As pessoas que avaliaram o destino como "muito bom" citaram fatores como: um bom lugar para fotos, com muita beleza, bucólico, passeio de barca pela Baía de Guanabara, contemplação da natureza, atrações mais acessíveis financeiramente, adequado para passeios de casais e ideal para crianças.

Analisando os comentários das pessoas que avaliaram o destino como "excelente" ou "muito bom", pode-se perceber que, ao mesmo tempo em que as qualidades do local são citadas, muitos fatos negativos, que podem influenciar na decisão de ir ou não à ilha e até na percepção negativa das pessoas quanto às condições locais de atrativos, são abordados. Esses fatos podem influenciar a decisão do turista quanto ao uso dos serviços e atrativos locais.

Em relação aos que classificaram o destino como "razoável", pontos positivos, como a arquitetura ou a opinião de que a ilha é um bom local para passar o tempo, são citados. Entre os pontos negativos mencionados estão: praias poluídas, precária infraestrutura, restaurantes caros, mal cheiro da baía por causa do esgoto in natura e água das praias imprópria para banho.

No quesito "ruim" são citados o mau cheiro, praias e barcas sujas, casas fechadas ou sendo alugadas e a percepção de que o local "parou no tempo". Para os respondentes do quesito "horrível" as queixas foram: lugar sujo, mal frequentado e completamente esquecido, sem estrutura para visitantes, crescimento de favelas, falta de serviços de praia como venda de água de coco e várias pessoas abordando os visitantes oferecendo serviços (passeios, restaurante e hotéis) na saída das barcas. 


\section{CONSIDERAÇÕES FINAIS}

O conhecimento do local deixa a constatação para o visitante de que o todo pode ser formado por partes que se inter-relacionam e dialogam, desenvolvendo um sistema onde beneficiar uma categoria seria como negar o todo ou torná-lo superior aos fragmentos. Há vários problemas que, resolvidos pelo poder público em conjunto com a comunidade e comerciantes, levariam a potencializar a atividade turística.

A hipótese do trabalho considerava que os turistas frequentam Paquetá em razão dos modelos de transporte que tornam a ilha única. No entanto, de acordo com a pesquisa in loco, pode-se afirmar a refutação da hipótese, pois os transportes não são os principais atrativos motivadores da visita ao local. Ainda se constatou que os fatores que potencializam a maior parte da visitação são a possibilidade de conhecer a ilha, realizar passeio cultural com familiares, parentes e amigos, lazer e fotos.

Embora os tipos de transportes da Ilha de Paquetá sejam meios que remetam os visitantes a momentos cinematográficos, literários, cenários de novelas e lugares únicos, alguns dos turistas não relacionaram o cenário de Paquetá com relações históricas, literárias e cenográficas, devido ao razoável ou pouco conhecimento sobre a ilha. Esse problema seria resolvido se em Paquetá tivesse pontos de informação turística e mais serviços de visitação, acompanhado de guias locais para quem não irá fazer os passeios de charretes ou eletrotáxi nos quais o condutor aborda a história e curiosidades da ilha. Os entrevistados relataram ter experimentado momentos e sensações já passados em suas vidas, o que estava previsto pela justificativa da pesquisa.

Para tornar positivas as condições da ilha, considerando serviços e infraestrutura, é fundamental que parcerias com órgãos especializados sejam estabelecidas com fins de excelência. Essa ação entrará em prática à medida que políticas públicas saírem do papel para serem colocadas em prática, com melhoramentos de serviços, cursos de capacitação e incentivos que devem entrar nas metas das políticas públicas.

\section{REFERÊNCIAS}

ARAUJO, N. (2016). Direito Internacional Privado: Teoria e Prática Brasileira. Porto Alegre: Revolução E-book.

BASTOS, P. P. (2012). Pelas ruas da Ilha de Paquetá. Veja Rio. Recuperado de http://abr. ai/2xNLDIh

BOTTON, A. (2003). A arte de viajar. Rio de Janeiro: Rocco.

BRASIL. Ministério do Turismo. (2010). Tour da experiência: cartilha completa. Brasília, DF: Instituto Marca Brasil.

BRASIL, V. S. (2007). Experiência de consumo: aspectos conceituais, abordagens metodológicas e agenda de pesquisa. XXXI Encontro da Anpad, Rio de Janeiro, 2007.

BRUNER, J. (1991). Actos de significado: más alla de la revolución cognitiva. Madrid: Alianza. DAVID, F. (2016). Prefeitura entrega 17 carros elétricos em Paquetá e dá fim à tração animal. Prefeitura do Rio de Janeiro. Recuperado de http://bit.ly/2yTVmKM

DAWSEY, J. C. (2005). Victor Turner e antropologia da experiência. Cadernos de Campo, 13, 163-176. doi: 10.11606/issn.2316-9133.v13i13p163-176 
ESTARQUE, M. (2015). Turistas estrangeiros consideram Brasil caro, diz diretor do TripAdvisor. Folha de São Paulo. Recuperado de http://bit.ly/2fE2v9A

GRABURN, N. H. H. (1989). Tourism: the sacred journey. In Smith, V. (Ed.). Hosts and guests: the anthropology of tourism (pp. 21-36). Philadelphia: University of Pennsylvania Press.

GERMINARI, G., \& Buczenko, G. (2012). História local e identidade: um estudo de caso na perspectiva da educação histórica. História \& Ensino, 8(2), 125-142.

GORDON, B. (1986). The souvenir: messenger of the extraordinary. Journal of Popular Culture, 20(3), 135-146.

HORN, G. B., \& Germinari, G. D. (2010). Ensino de história e seu currículo: teoria e método. Petropólis, RJ: Vozes.

IBGE. (2010). Questionário Censo 2010. Recuperado de https://censo2010.ibge.gov.br/

ISHERWOOD, B. (2004). O mundo dos bens: para uma antropologia do consumo. Rio de Janeiro: UFRJ.

KRIPPENDORF, J. (2003). Sociologia do turismo: para uma nova compreensão do lazer e das viagens. São Paulo: Aleph.

LARAIA, R. B. (2001). Cultura: um conceito antropológico. Rio de Janeiro: Jorge Zahar.

LES Guides Bleus. (1955). Rio de Janeiro et ses environs. Paris: Librairie Hachette.

PANOSSO Netto, A., \& Gaeta, C. (2010). Turismo de experiência. São Paulo: Senac.

PEZZI, E.; Vianna, S. L. G. (2015). A experiência turística e o turismo de experiência: um estudo sobre as dimensões da experiência memorável. Revista Turismo em Análise, 26(1), 165-187.

PINE, B. J., \& Gilmore, J. H. (1999). The experience economy: work is theatre \& every business a stage. Massachusetts: Harvard Business School Press.

RUSCHMANN, D. V. M. (2000). 0 turismo rural e o desenvolvimento sustentável. In Almeida, J. A., Froehlich, J. M., \& Riedl, M. (Org.). Turismo rural e o desenvolvimento sustentável. Campinas, SP: Papirus.

SALDANHA, L., Fraga, C., \& Santos, M. P. S. (2015). Discussões preliminares sobre serendipidade, bicicleta e turismo envolvendo a Ilha de Paquetá no Rio de Janeiro (RJ). Caderno Virtual de Turismo, 15(3), 378-389.

SCHMITT, B. H. (1999). Experiential marketing. New York: Free Press.

SEBRAE. (2016). Turismo vivencial é meta do projeto Economia da Experiência. Recuperado de http://bit.ly/2xctjiy

SILVA, M. G. L. (2004). Cidades turísticas: identidades e cenários de lazer. São Paulo: Aleph.

TRIGO, L. G. G. (2010). A viagem como experiência significativa. In Panoso Netto, A., \& Gaeta, C. Turismo de experiência. São Paulo: Senac.

TRIPADVISOR. (2016). Ilha de Paquetá. Recuperado de http://bit.ly/2g5Buw7

TURNER, J. C., Tajfel, H., \& Turner, J. C. (1986). The social identity theory of intergroup behaviour. In Worchel, S., \& Austin, W. G. (Eds.). Psychology of intergroup relations (pp. 7-24). Chicago: Burnham.

TURNER, M.G. (1989). Landscape ecology: the effect of pattern on process. Annual Review of Ecology and Systematics, 20, 171-197. Recuperado de http://bit.ly/2hIHPl5

URRY, J. (1999). O olhar do turista. (Carlos E. M. de Moura, trad.). São Paulo: Senac. VIVERET, P. (2006). Reconsiderar a riqueza. Brasília, DF: Universidade de Brasília. 